\title{
Simulations Of Temperatures, Residual Stresses, And Porosity Measurements In Spray Formed Super Alloys Tubes
}

\author{
Reinhard Ristau ${ }^{1}$, Andreas Becker ${ }^{2}$, Volker Uhlenwinkel $^{3}$, Reinhold Kienzler ${ }^{1}$ \\ ${ }^{1}$ BIME - Bremen Institute for Mechanical Engineering, University of Bremen \\ Am Biologischen Garten 2, 28357 Bremen, Germany \\ ${ }^{2}$ Mechanical Engineering, University of Bremen \\ Badgasteiner Str. 3, 28359 Bremen, Germany \\ ${ }^{3}$ Institute for Materials Science, Badgasteiner Str. 3, 28359 Bremen, Germany
}

Keywords: Spray Forming, Simulation, Residual Stresses, Porosity

\begin{abstract}
Spray Forming is a technology to produce near net shape components and preforms. A simulation tool for the temperature distribution which incorporates all necessary sub steps (metal deposition on the substrate, heat transfer across the surface by convection and radiation) is developed to calculate residual stresses during the different process steps. The resulting temperature distribution was used to calculate the stresses during all process stages. Thermal histories of temperatures at certain positions will be shown. The dependency of the residual stress on the thermal history of the material was examined. Mainly at the interface substrate/deposit, a region with elevated porosity was observed. Porosity measurements will be presented.
\end{abstract}

\section{Introduction}

Spray forming combines two distinct processes. In the first step, liquid metal is atomized into a spray cone of droplets. The impinging droplets form a near net shape product on a substrate in the second step. In contrast to spray formed billets, (in which the surface temperature is mostly constant) the substrate surface temperature just ahead of the spray cone is a strong function of time. Therefore, the obtained material density or the porosity is a function of the surface temperature. Porosity measurements of super alloy rings were reported in [1]. The results show that at temperatures above $1100^{\circ} \mathrm{C}$, low porosity is measured. High convection coefficients in the vicinity of the spray cone cause a temperature increase for initially cold substrates and a temperature drop for initially hot substrates. Mathematical models for the temperature distributions in the spray formed tubes were created $[2,3,4,5,6]$. A detailed analysis of heat exchange phenomena on small time scales is given by [3]. The temperature distribution in substrate and deposit act as a load for the developing residual stresses. Due to the difficulties in simulating stresses in spray formed deposits, only a few papers have been presented [7, 8, 9]. Mechanical properties for IN718 are reported for temperatures up to $1100^{\circ} \mathrm{C}$ [10]. The uncertainties in the mechanical properties cover a small temperature range, from $150 \mathrm{~K}$ to the solidus temperature of the material. The resulting stresses are mainly affected by thermal strains. Specifically, they depend on the heating and cooling rates during the spray process, and later on post spray conditions. Therefore, the knowledge of the temperature distribution during the spray forming process, as well as the behavior of temperature during heat treatment and cooling processes is of great importance in the understanding of the development of residual stresses. 


\section{Simulations}

The mathematical model has to be able to describe the growth process of impinging semisolid metal particles on a (preheated) rotating substrate tube which passes through a spray cone. Table I summarizes the overall geometrical data. The heater was designed for both preheating purposes as well as for heat treatment reasons. The model consists of three parts. In part 1, the geometrical modeling of substrate and deposit is conducted. Part 2 is responsible for calculating the temperature distribution during decomposition, heat treatment and cooling. In part 3, the resulting stresses caused by temperature loading are calculated.

Table I. Overall Geometry used in the Simulations.

\begin{tabular}{|c|c|c|c|}
\hline inner substrate radius & $45 \mathrm{~mm}$ & substrate length & $500 \mathrm{~mm}$ \\
\hline outer substrate radius & $50 \mathrm{~mm}$ & deposit length & $400 \mathrm{~mm}$ \\
\hline deposit thickness & $19 \mathrm{~mm}$ & heater length & $500 \mathrm{~mm}$ \\
\hline
\end{tabular}

\section{Geometry Model}

The growth of the deposit for a fixed distance between the atomizer nozzle and the deposition plane is described by the radial distribution of the mass flux density $(\dot{m})$. This is provided by [11].

$$
\dot{m}(r)=\dot{m}_{o} \exp \left\{-\ln (2)\left[\frac{r}{r_{o 5}}\right]^{a}\right\}
$$

Where $\dot{m}_{o}$ is the mass flux density at the spray cone axis, $r_{o 5}$ is the half value radius, and $a$ is an exponent whose value is set to 1.4. The total mass flow is obtained by integrating equation 1 with respect to the radius. For numerical reasons, the integration is limited to a maximum radius $r_{\max } \approx 3 r_{o 5}$ (spray cone boundary).

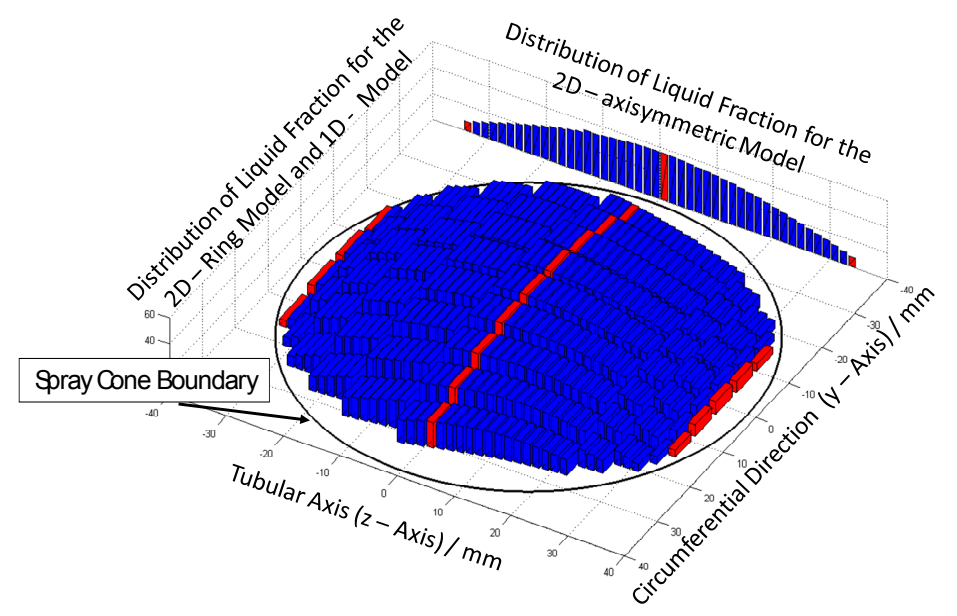

Figure 1. Schematic mass / energy distribution in the spray cone. 
Figure 1 demonstrates the integration process employed for a liquid fraction distribution. The $y, z$-plane is perpendicular to the spray cone axis and is at a certain distance away from the atomizer nozzle. Beyond the spray cone boundary, the mass flow is set to zero. The impinging mass flow $\left(m^{*}(y, z)\right)$, shaped in a rectangle of size $\Delta y, \Delta z$, is given by equation 2. A sticking efficiency $\left(s_{\text {eff }}\right.$ ) takes into account the overspray and the (numerical) loss of mass flow due to the integration algorithm [3]. The integration for a constant $z$-position results in a distribution used in the $2 \mathrm{D}$ - axisymmetric model.

$$
m^{*}(y, z)=s_{\text {eff }} \dot{m}_{o} \int_{z_{i}}^{z_{i+1}} \int_{y_{j}}^{y_{j+1}} \exp \left\{-\ln (2)\left[\frac{\sqrt{y^{2}+z^{2}}}{r_{o 5}}\right]^{a}\right\} d y d z
$$

\section{Temperature Calculations}

For an axisymmetric model in cylindrical coordinates, the partial differential equation for the temperature field due to conduction is given by equation 3. The equation also includes the presence of a heat sources $\dddot{q}[12]$.

$$
\rho c \frac{\partial T}{\partial t}=\frac{1}{r} \frac{\partial}{\partial r}\left(k r \frac{\partial T}{\partial r}\right)+\frac{\partial}{\partial z}\left(k \frac{\partial T}{\partial z}\right)+\dddot{q}
$$

Where $\rho$ is the density, $c$ is the specific heat capacity, and $k$ is the thermal conductivity. The necessary thermal material properties were taken from [13].

\section{Initial and Boundary Conditions}

The enthalpy flow $(\dot{H}(y, z))$ associated with the metal mass flow for a quadratic distribution of the specific enthalpy $h(y, z)$ with respect to the coordinates $y, z$ is given by:

$$
\dot{H}(y, z)=\int_{z_{i}}^{z_{i+1}} \int_{y_{j}}^{y_{j+1}} \dot{m}(y, z) h(y, z) d y d z
$$

with

$$
h(y, z)=h_{\max }-\frac{h_{\max }-h_{s o l}}{r_{\max }^{2}}\left(y^{2}+z^{2}\right)
$$

The maximum value for the specific enthalpy $h_{\max }$ at the spray cone axis is adjusted to maintain an overall liquid fraction of $30 \%$. This is done under the assumption that the specific enthalpy for $r_{\max }$ equals the specific enthalpy at solidus temperature $h_{\text {sol }}=h\left(T_{\text {sol }}\right)$ at the spray cone boundary. The liquid fraction distribution in the spray cone is shown in Figure 1. To calculate the initial temperature of a new deposit layer, a linear function of the specific enthalpy with respect to the temperature between solidus and liquidus temperature is assumed. The initial temperature of the substrate is either room temperature or the substrate is heated up to $1100^{\circ} \mathrm{C}$. 
At the inner radius of the substrate, adiabatic conditions were assumed. Convection $\left(\dot{Q}_{c o n}\right)$ and radiation $\left(\dot{Q}_{\text {rad }}\right)$ were applied as boundary conditions over the remaining surface:

$$
\dot{Q}_{\text {con }}=A_{\text {dep }} h\left(T_{\text {surf }}-T_{\text {amb }}\right) \text { and } \dot{Q}_{\text {rad }}=\sigma \varepsilon A_{\text {dep }}\left(T_{\text {surf }}^{4}-T_{\text {amb }}^{4}\right)
$$

Where $A_{d e p}$ is the surface area of the deposit (including the outer surface of the unsprayed substrate), $T_{\text {surf }}, T_{a m b}$ are the surface and ambient temperatures, $\sigma$ is the Stephan-Boltzmann constant, and $\varepsilon$ is the emissivity. For the heat transfer coefficient $h$, a symmetric function of the distance from the spray cone axis was chosen. The substrate and deposit pass through the heat transfer coefficient distribution, and experience different heat transfer coefficients at different time steps. The emissivity $\varepsilon$ was set to 0.5 .

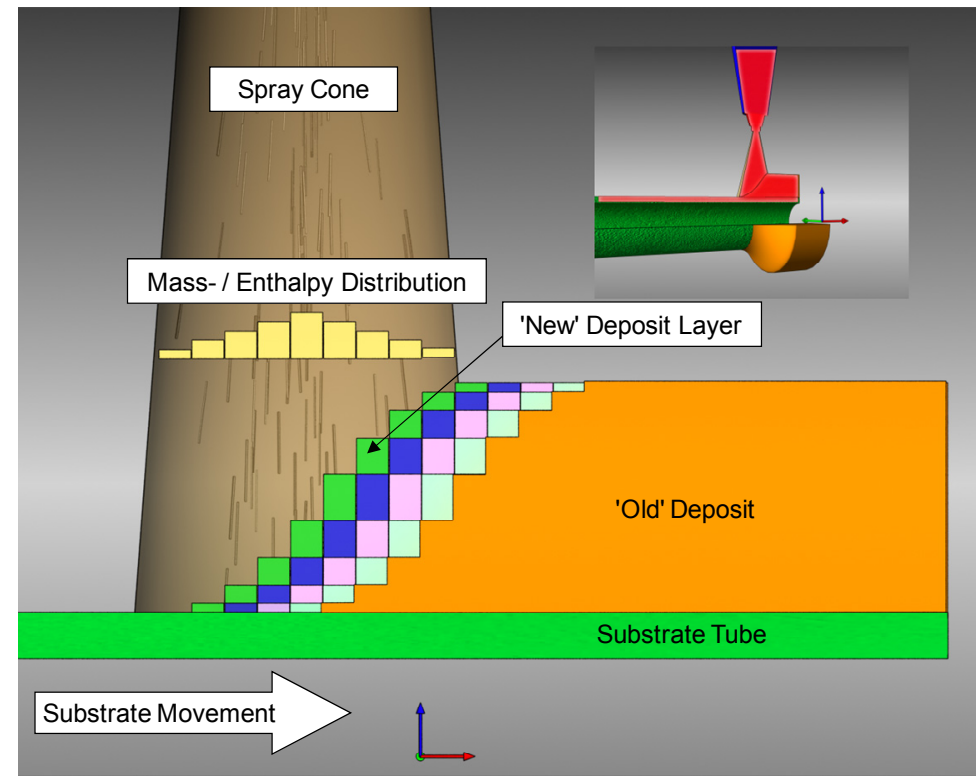

Figure 2. Spray process.

Figure 2 is an illustration of the spray process. In the upper right corner, a 3D animation of the process can be seen. The red marked area is part of the $2 \mathrm{~d}-$ axisymmetric model. During the integration time (approx. 1s), mass and enthalpy were collected from the spray cone. In the new time step, mass and enthalpy were added to the finite element model, with the green bars denoted as the 'new' deposit layer. The initial temperature (corresponding to the specific enthalpy) was applied to the new layer and the boundary conditions were updated for the entire model. Using the updated boundary conditions, the temperature field was calculated according to equation 3 . During the active time step, material was collected from the spray cone (yellowish brown bars) to be added to the model in the next time step.

\section{Heat Treatment / Cooling Conditions}

An inductive heater was used for preheating the substrate and/or applying a heat treatment process to the sprayed tube. After the spray process, the deposit was moved back to the heater. In Figure 3, a piece of a cross section of substrate/deposit, heater insulation and induction coil is 
shown. The boundary conditions cause a thermal gradient at the deposit surface that is equal to the heat flow due to convection and radiation over the surface. The heat flow was collected at the surface of the inductor insulation and was transferred by conduction to the inductor coils. These were cooled to a certain temperature. For the heat treatment process, the power to the inductive heater was adjusted to reach the desired annealing temperature (e.g. $1000^{\circ} \mathrm{C}$ or $\left.1200^{\circ} \mathrm{C}\right)$. In this case, equation 3 was solved by taking a heat source into account. The heat source $\dddot{q}$ decayed exponentially, due to the characteristic of an inductive heater. Equilibrium was reached when the heat losses due to convection and radiation equaled the energy input to the heater.

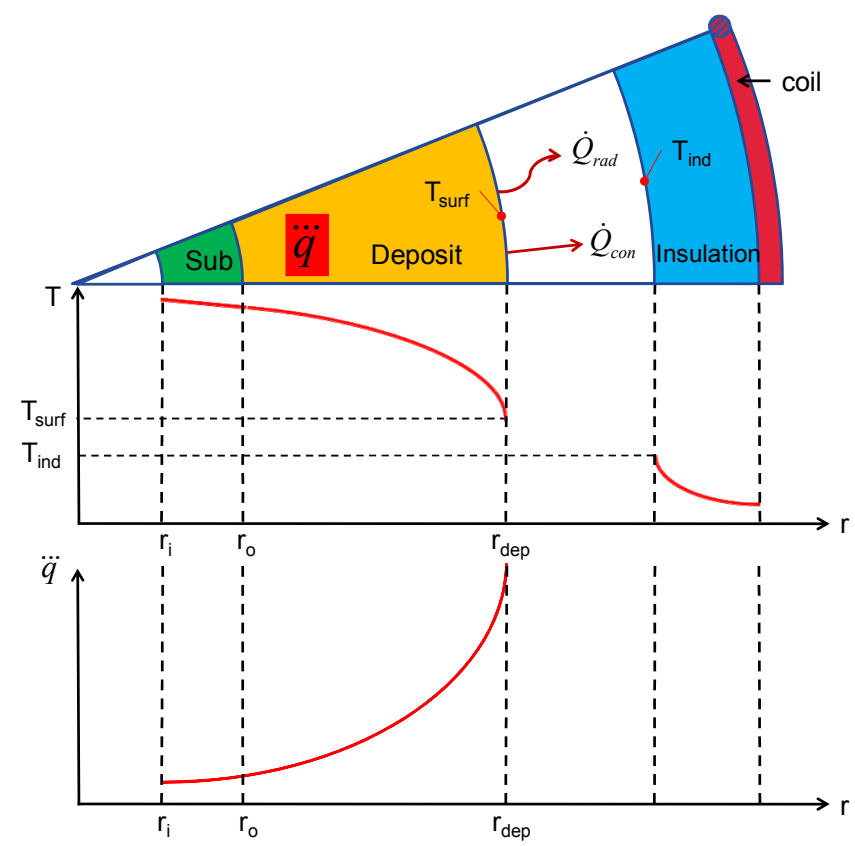

Figure 3. Schematic view of the temperature and heat source distribution of a piece of a cross section of substrate and deposit.

Table II. Applied Boundary Conditions.

\begin{tabular}{|c|c|c|c|}
\hline \multirow[t]{2}{*}{ Item } & $\begin{array}{c}\text { Heat Transfer Coefficient } \\
W /\left(\mathbf{m}^{2} \mathbf{K}\right) \\
\end{array}$ & $\begin{array}{c}\text { Ambient Temperature } \\
{ }^{\circ} \mathrm{C} \\
\end{array}$ & Radiation \\
\hline & \multicolumn{3}{|c|}{ Spray forming process } \\
\hline \multirow[t]{2}{*}{ Forced Convection } & $\begin{array}{l}650 \text { to } 200 \\
\text { (function of the tubular } \\
\text { coordinate) }\end{array}$ & $\begin{array}{l}400 \text { to } 200 \\
\text { (function of the tubular } \\
\text { coordinate) }\end{array}$ & yes \\
\hline & \multicolumn{3}{|c|}{ Cooling Condition } \\
\hline Natural Convection & 50 & 50 & yes \\
\hline Forced Convection & $\begin{array}{l}650 \text { to } 200 \\
\text { (function of the tubular } \\
\text { coordinate) }\end{array}$ & 50 & yes \\
\hline $\begin{array}{l}\text { Predefined Cooling Rate } \\
\text { and Heat Treatment }\end{array}$ & 50 & inductor temperature & yes \\
\hline
\end{tabular}

The initial time step in the simulation (heating or cooling) was estimated so that the overall increase or decrease of deposit and substrate temperature was $1 \mathrm{~K}$. After achieving the desired 
temperature, the heater power was reduced to a new equilibrium value. In the simulation, the temperature steps were $200 \mathrm{~K}$ each (Figure 6). One simulation was performed by applying a predefined cooling rate of $0.02 \mathrm{~K} / \mathrm{s}(72 \mathrm{~K} / \mathrm{h})$ (c.f. Figure 7$)$.

In the heat treatment case, the boundary conditions for convection and radiation were changed. The ambient temperature became the transient temperature $T_{\text {ind }}$ at the inner surface of the heater. The equation for the radiation heat exchange took into account the geometry from the deposit and heater [14].

$$
\dot{Q}_{\text {con }}=A_{\text {dep }} h\left(T_{\text {surf }}-T_{\text {ind }}\right) \text { and } \dot{Q}_{\text {rad }}=\frac{\sigma}{\frac{1}{\varepsilon}+\frac{A_{\text {dep }}}{A_{\text {ind }}}\left(\frac{1}{\varepsilon}-1\right)} A_{\text {dep }}\left(T_{\text {surf }}^{4}-T_{\text {ind }}^{4}\right)
$$

\section{$\underline{\text { Stress Calculations }}$}

The mechanical properties were taken from [10]. Parameters for a tri-linear kinematic hardening model were extracted from the data and applied as a material model. The linear elastic behavior was valid to up to $90 \%$ of the yield stress for the corresponding temperature. The second point was the yield stress, which correlated to the elastic strain plus $0.2 \%$ plastic strain. Finally, the third point was given by the tensile strength and a total strain of $15 \%$. Poisson's ratio and the Young's modulus were temperature dependant. The coefficient of thermal expansion was assumed to be constant. Figure 4 shows the used stress - strain relations. Solid lines are based on [10], and the dashed lines are estimated for temperatures above $1093^{\circ} \mathrm{C}$. The calculated temperature fields were applied as loads to the mechanical model at every time step.

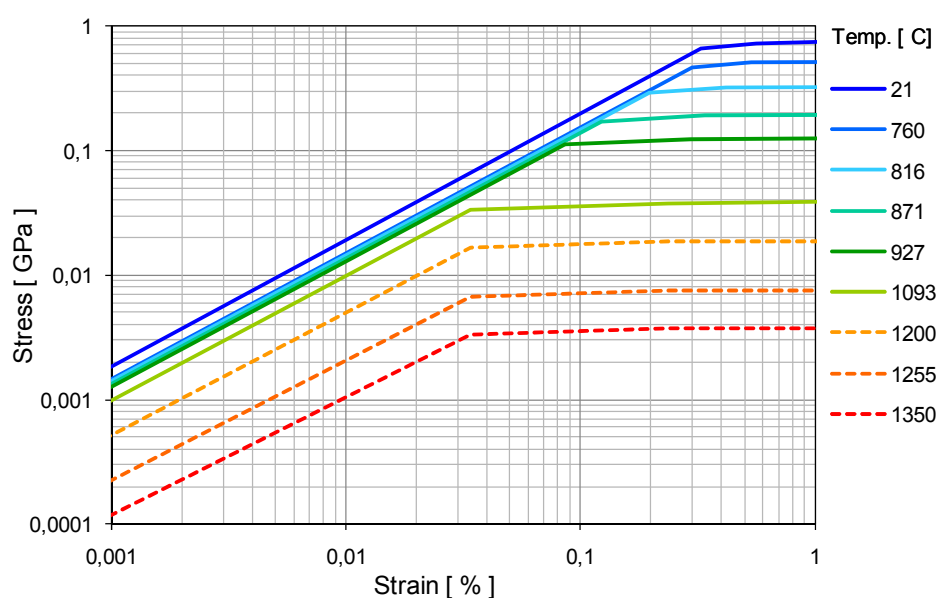

Figure 4. Stress / strain curves used in the simulations.

\section{Experimental set-up}

For the production of spray formed materials on a technological scale, a spray forming plant with a capacity of $20 \mathrm{~L}$ of liquid material was used. The experimental set-up is shown schematically in Figure 5. Inductive melting under inert atmosphere of argon at ambient pressure was used to avoid the oxidation of the molten metal. The pouring system supplied a tundish with a constant melt flow of $970 \mathrm{~kg} \mathrm{~h}^{-1}$. A scanning free-fall atomizer was used for the atomization of the melt, 
which flowed through a $5.5 \mathrm{~mm}$ diameter outlet at the bottom of the tundish. Nitrogen and argon with gas flows of about $1010 \mathrm{~kg} \mathrm{~h}^{-1}$ were used for the atomization. The alloy was superheated to $150 \pm 10 \mathrm{~K}$ above the liquidus temperature and was held there for 30 minutes to achieve homogenization. Afterwards, the melt was poured into the pre-heated tundish. The melt and tundish temperatures were kept the same to avoid premature freezing of the melt. Located $400 \mathrm{~mm}$ below the atomizer is the substrate tube. The diameters and length of the substrate were 88 and 102 x $500 \mathrm{~mm}$, and the wall thickness was $5 \mathrm{~mm}$. The substrates were preheated using an inductive heater $(150 \mathrm{~kW})$ capable of temperatures up to $1200^{\circ} \mathrm{C}$.
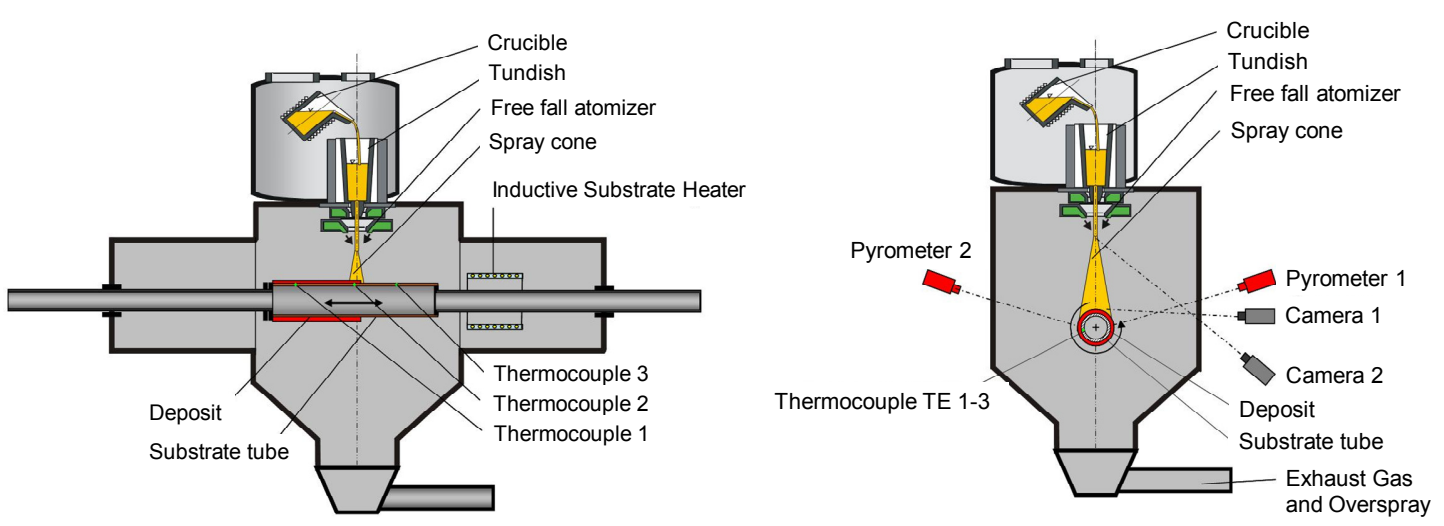

Figure 5. Schematic of the process and measuring devices.

The experiment was observed via two cameras which monitored the deposition process and the melt outlet. Using two pyrometers, the surface temperature of the deposit was recorded. The scanning pyrometer 2 covered a range of about $250 \mathrm{~mm}$. Three thermocouples measured the temperature at the interface of substrate and deposit. The substrate velocity varied from 1.5 to $3 \mathrm{~mm} / \mathrm{s}$ and the rotational frequency was $2.5 \mathrm{~Hz}$.

\section{Results}

\section{Temperature Simulations}

The performed simulations and the cooling conditions of the experiments are summarized in Table III. Initial substrate temperatures at room temperature and preheated to $1100^{\circ} \mathrm{C}$ were examined. The cooling conditions after the spray forming process were natural or forced convection (Table II). In the heat treatment case, the deposit was heated up to an annealed temperature of either $1000^{\circ} \mathrm{C}$ or $1200^{\circ} \mathrm{C}$. After reaching the desired temperature, power to the heater was reduced to decrease the temperature in $200 \mathrm{~K}$ steps. When the deposit temperature reached $200^{\circ} \mathrm{C}$, forced convection was applied as a boundary condition. In the case of the predefined cooling rate, the heater power was reduced gradually to maintain the desired cooling rate. Radiation was considered in all stages. The location of the reference points for the thermal history were at a fixed position, approximately in the middle of the length of the tube. Their radial positions were at the substrate surface and at the maximum radial deposit surface. The reference point on the substrate surface arrived at the edge of the spray cone $80 \mathrm{~s}$ after the start of the spray forming process. At a time of 23 seconds later, the points had passed though the cone, and the deposit had reached the height of the second reference point. 
Table III. Cooling Parameters in the Simulations.

\begin{tabular}{|l|l|}
\hline \multicolumn{2}{|c|}{ Initial Substrate Temperature } \\
\hline \multicolumn{1}{|c|}{$\mathbf{2 0}^{\circ} \mathbf{C}$} & \multicolumn{1}{c|}{$\mathbf{1 1 0 0}^{\circ} \mathbf{C}$} \\
\hline natural convection & natural convection \\
\hline forced convection & forced convection \\
\hline annealed $1000^{\circ} \mathrm{C}$ & annealed $1000^{\circ} \mathrm{C}$ \\
\hline annealed $1200^{\circ} \mathrm{C}$ & annealed $1200^{\circ} \mathrm{C}$ \\
\hline & predefined cooling rate $0.02 \mathrm{Ks}^{-1}$ \\
\hline
\end{tabular}

Results of the Temperature Calculation The simulation started with an initial substrate temperature. During a 20s period, the substrate moved from the heater to the spray cone. Natural convection and radiation were applied as boundary conditions. Thereafter, the spray forming process started (left green line in Figure 6). The process finished 153s later (right green line), after which time the cooling or heat treatment process started immediately.

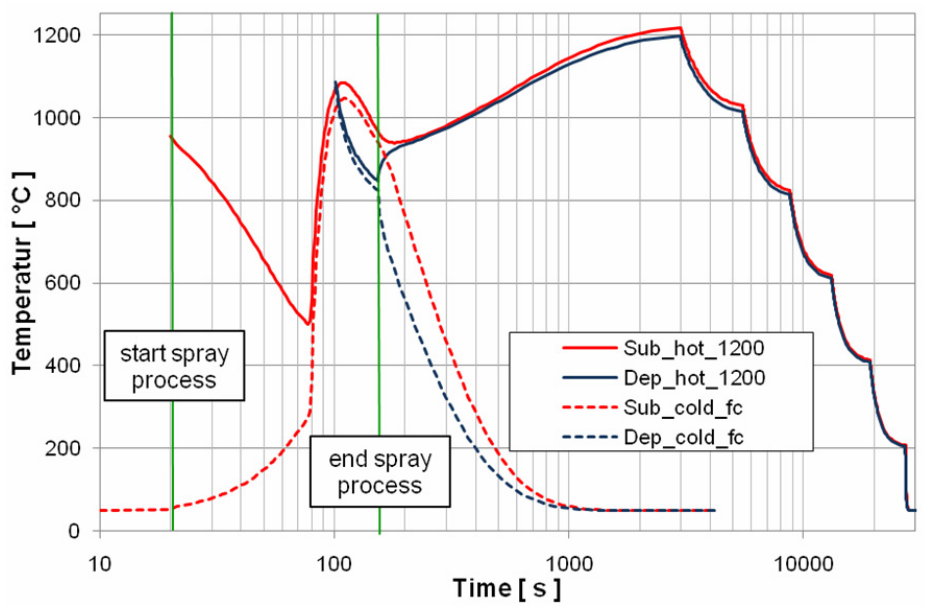

Figure 6. Temperature history at two reference points in two different simulations.

In Figure 6, the thermal history for two different simulations are shown on a logarithmic time scale. The dashed lines show the thermal history at the substrate/deposit interface (Sub_cold fc) and at the deposit surface (Dep_cold_fc). $50^{\circ} \mathrm{C}$ was the initial substrate temperature. The solid lines (xxx_hot_1200) show the results from an initial substrate temperature of $1100^{\circ} \mathrm{C}$.

The initially hot substrate was cooled down by the atomizer gas and by radiation, whereas the cold substrate was heated up. When the reference point at the substrate surface reached the edge of the spray cone, the temperature difference was about $300 \mathrm{~K}$. This temperature difference was reduced to $30 \mathrm{~K}$ after the reference point has passed the spray cone (red lines), due to the higher heat demand of the colder substrate. The thermal history at the reference point at the deposit surface started 23s later. For the differences in surface temperature (blue lines), the effect of different initial substrate temperatures were less significant. This is due to the total thermal mass of the deposit and substrate. At the end of the spray process, a small temperature difference had established.

At the end of the spray forming process (right green line), the temperature difference inside the deposit was of about $150 \mathrm{~K}$. For the simulation with forced convection as cooling condition, this 
difference lasted for the next $150 \mathrm{~s}$. At that time the temperature decreased to $300^{\circ} \mathrm{C}$. At $1000 \mathrm{~s}$, the deposit had a final temperature of $50^{\circ} \mathrm{C}$. In the case of the heat treatment process, the temperature difference between substrate and deposit surface quickly vanished ( $\sim 50 \mathrm{~s})$.

Cooling Rates In Figure 7, heating and cooling rates for the thermal histories of Figure 6 (hot substrate) and for a predefined cooling rate of $0.02 \mathrm{~K} / \mathrm{s}$ are shown. The thermal histories for both simulations (during spray forming and annealing to $1200^{\circ} \mathrm{C}$ ) were almost identical. The exception was for the predefined cooling rate, in which the annealing period is extended by approx. $1 / 2 \mathrm{~h}$. As such, the final heating rate was reduced from $7 * 10^{-3} \mathrm{~K} / \mathrm{s}$ to $1 * 10^{-3} \mathrm{~K} / \mathrm{s}$, which resulted in a surface temperature difference of only a few degrees. The left and bottom axis correspond to the predefined cooling rate (PCR), and the right and top axis to the $200 \mathrm{~K}$ step temperature changes after annealing (c.f. Figure 6). For the PCR-conditions, it took approximately $1 / 2 \mathrm{~h}$ to reach the desired rate. The rate then remained constant throughout the cooling period. When the temperature reached $200^{\circ} \mathrm{C}(\sim 55,000 \mathrm{~s})$, the heater was turned off and the deposit continued to cool slowly inside the heater.

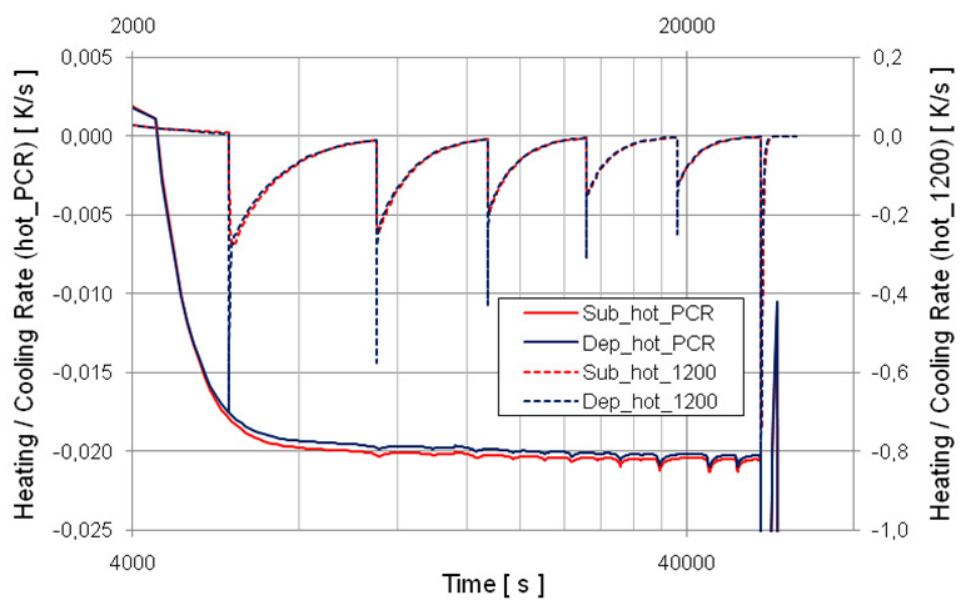

Figure 7. Cooling rates for an annealing temperature of $1200^{\circ} \mathrm{C}$ and different cooling conditions.

In the stepwise cooling process, the cooling rate increased to $0.7 \mathrm{~K} / \mathrm{s}$ for a very short period, then decreased to nearly zero. At lower temperatures, the peak values decreased due to the smaller net heat flux compared to higher surface temperatures. At $200^{\circ} \mathrm{C}$, forced convection was applied, which resulted in a step increase in the cooling rate.

Residual Stresses The development of the hoop stress for annealing temperatures of both $1000^{\circ} \mathrm{C}$ and $1200^{\circ} \mathrm{C}$ and for an initial substrate temperature of $1100^{\circ} \mathrm{C}$ are shown in Figure 8. At the lower left corner, the hoop stress at the end of spray forming is shown. The temperature reference points (c.f. chapter 'Temperature Simulations') are in the middle of length of the ring. $40 \mathrm{~mm}$ was the ring length, it represents approximately $1 / 10$ of the entire deposit. The stress distribution for the lower annealing temperature $\left(1000^{\circ} \mathrm{C}\right)$ and for different deposit temperatures at the cooling process (spray end, $(1200), 1000,400,50^{\circ} \mathrm{C}$ ) was arranged at the lower row (blue arrows). The upper row corresponds to an annealing temperature of $1200^{\circ} \mathrm{C}$. At the end of the spray forming process, the absolute stresses were around $\pm 60 \mathrm{MPa}$. The annealing process reduced the residual stress. During cooling the stress gradually increased. This resulted in tensile 
stresses of $70 \mathrm{MPa}\left(1200^{\circ} \mathrm{C}\right)$ and $110 \mathrm{MPa}$ and compressive stresses of $120 \mathrm{MPa}\left(1200^{\circ} \mathrm{C}\right)$ and $160 \mathrm{MPa}$ in the substrate.

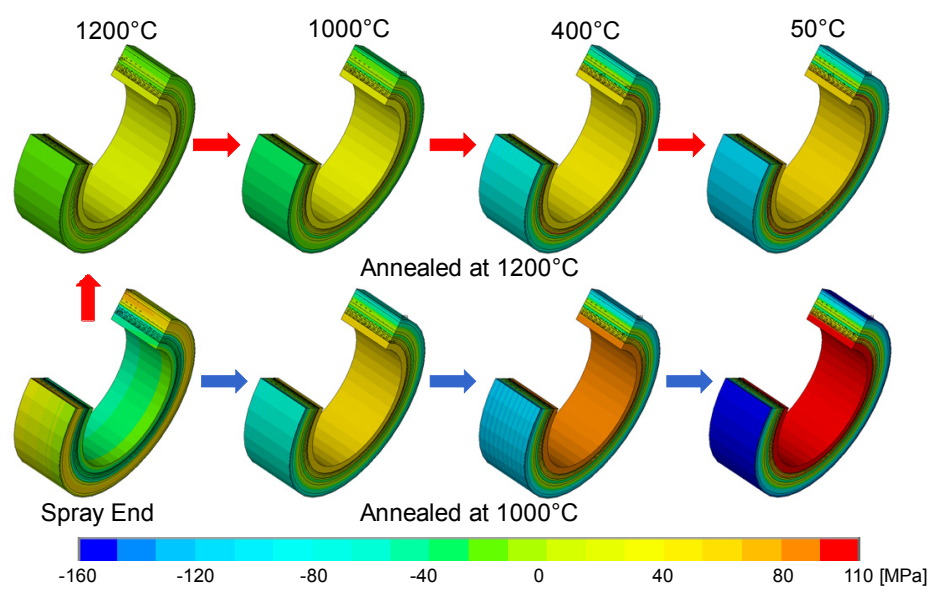

Figure 8. Hoop stress development for annealing temperatures $1000^{\circ} \mathrm{C}$ and $1200^{\circ} \mathrm{C}$.

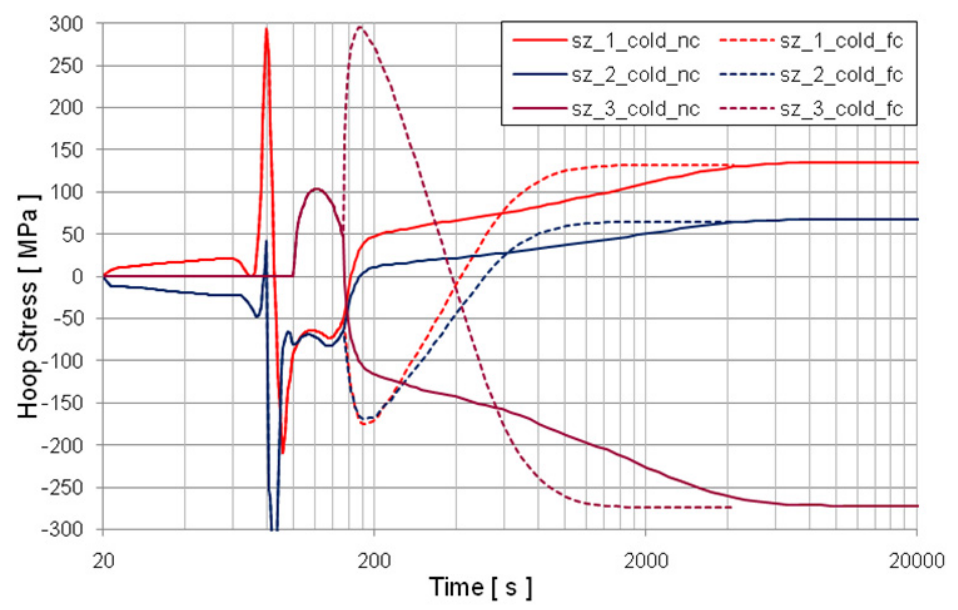

Figure 9. Hoop stress history for initially cold substrates, cooling condition: forced an natural convection, no annealing.

Figure 9 shows the hoop stress distribution at three points $(1=$ inner radius substrate, $2=$ interface substrate/deposit, $3=$ deposit surface). The cooling conditions were natural convection (nc) and forced convection ( $\mathrm{fc}$ ), and the initial substrate temperature was $50^{\circ} \mathrm{C}$ (cold). Up until the end of the spray process $(153 \mathrm{~s})$, the conditions for both simulations were identical. At $t=20 \mathrm{~s}$, the spray process began and caused small compressive stresses at the outer substrate surface. It also caused tensile stresses at the inner substrate surface as a result of the temperature difference between inner and outer surface (c.f. Figure 6). The outer surface was heated up due to the hot atomizer gas, whereas the inner substrate surface remained colder. The situation changed when the spray cone reached the reference points. Apart from some peaks, the hot deposit generated compression inside the substrate. When all reference points were covered with deposit, tensile stress was observed at the deposit surface. This was due to the higher cooling rate at the surface compared to those of subjacent layers. These layers act as strain constraints for the material at the surface. 
At the beginning of the cooling process (153s), differences between the two simulations were established. For the dashed lines ( $\left.x x x \_f c\right)$, the forced convection generated high tension at the deposit surface and moderate compression in the substrate. The temperature difference between the deposit surface and interface substrate/deposit was about 200K (Figure 6). With reducing temperature differences, the thermal strain at the substrate decreased and caused tension at the substrate due to strain constraints. This, in turn, caused compression at the outer region of the deposit.

For the cooling conditions with natural convection, the same conclusion as above was achieved, except tension was not seen at the deposit surface. The final stress values were, in principle, the same (+140Mpa / -275MPa).The chosen cooling conditions didn't affect the final residual stresses.

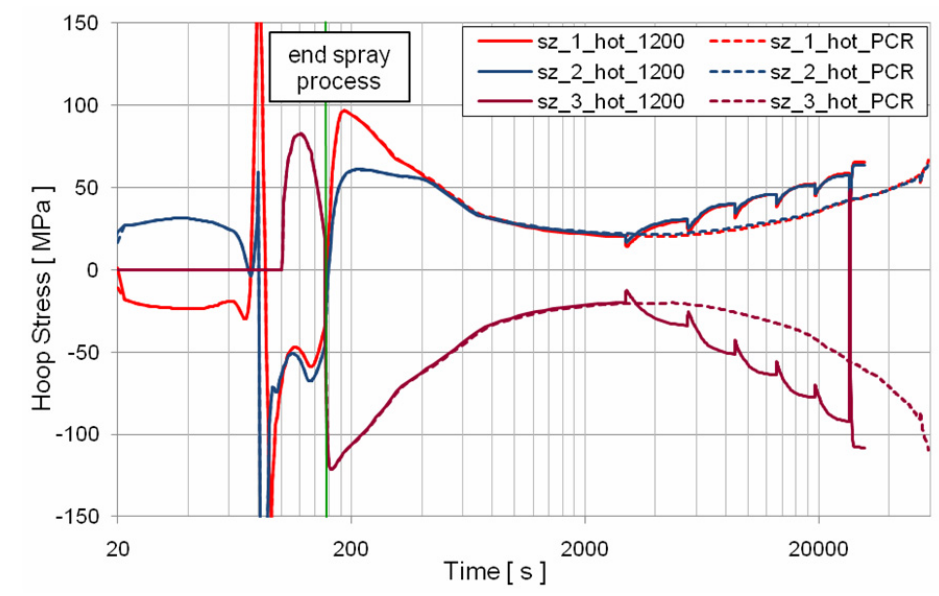

Figure 10. Hoop stress history for initially hot substrates, cooling condition: step temperatures and predefined cooling rate, annealing temperature $1200^{\circ} \mathrm{C}$.

In Figure 10, results in the case of heat treatment are presented. The initial substrate temperature was $1100^{\circ} \mathrm{C}$. After the spray process, the deposit was annealed in the heater. Upon reaching the desired temperature of $1200^{\circ} \mathrm{C}$, the material was either cooled down in steps of $200 \mathrm{~K}$ (solid lines, xxx_1200, c.f. Figure 6 for the temperature history) or cooled down at a predefined cooling rate (dashed lines, $\mathrm{xxx}$ _PCR, for the cooling rates of both simulation c.f. Figure 7). Within the period prior to the spray cone reaching the reference point, the sign of the stresses changed. This was due to the colder outer surface compared to the inner surface of the substrate, as the surface temperature of the substrate was higher than the temperature of the atomizer gas. The stress values were of the same order of magnitude as those of to the cold substrate case. The absolute values of tension and compression in the substrate and at the deposit surface were $\sim 25 \mathrm{MPa}$ lower than in the cold case.

Deposit surface heating was observed at the beginning of the annealing process, whereas the material was exposed to a cooling process at the substrate. Due to the corresponding thermal strain increments, the sign of the stresses changed. Also, the differences in the stress values between the inner and outer radius of the substrate tube were significant. This effect vanished after a few minutes, as the temperature became homogenous in the substrate. The absolute stress values were reduced continuously until the temperature was at $1200^{\circ} \mathrm{C}$. During the cooling 
process, peaks in the stress curves were observed for the step temperature procedure (solid lines, xxx_1200). When the temperature changed, peaks occurred in the curves. The peaks tended to have smaller absolute stress values. Afterwards, an increase in absolute stress values can be seen. When the deposit was cooled down to $200^{\circ} \mathrm{C}$, forced convection was applied to the deposit and large peaks in the stress values occurred. In the case of a predefined cooling rate (dashed lines, xxx_PCR) the same minimum stress values were observed. The cooling started at $t \approx 4,500 \mathrm{~s}$. Thereafter, the absolute stress values increased continuously and showed nearly the same values as in the step temperature procedure.

In Figure 11, the stress development as a function of the process temperature for the initially hot substrate are summarized for different cooling conditions. SE denotes the situation at the end of the spray forming process. The solids lines mark the runs with heat treatment and the dashed lines represent the runs without heat treatment. For the runs without heat treatment, the stresses were taken when the average temperature of substrate and deposit was close to the process temperatures. The starting point for all runs was the same. In the case of heat treatment, lower stress values for higher annealing temperatures were observed (xxx_1000, xxx_1200). The curves for the predefined cooling rate (xxx_PCR) are exactly the same as those of the run with the step temperature procedure (xxx_1200). The stress development for the runs without heat treatment showed very different values during the cooling process, whereas the final values were identical.

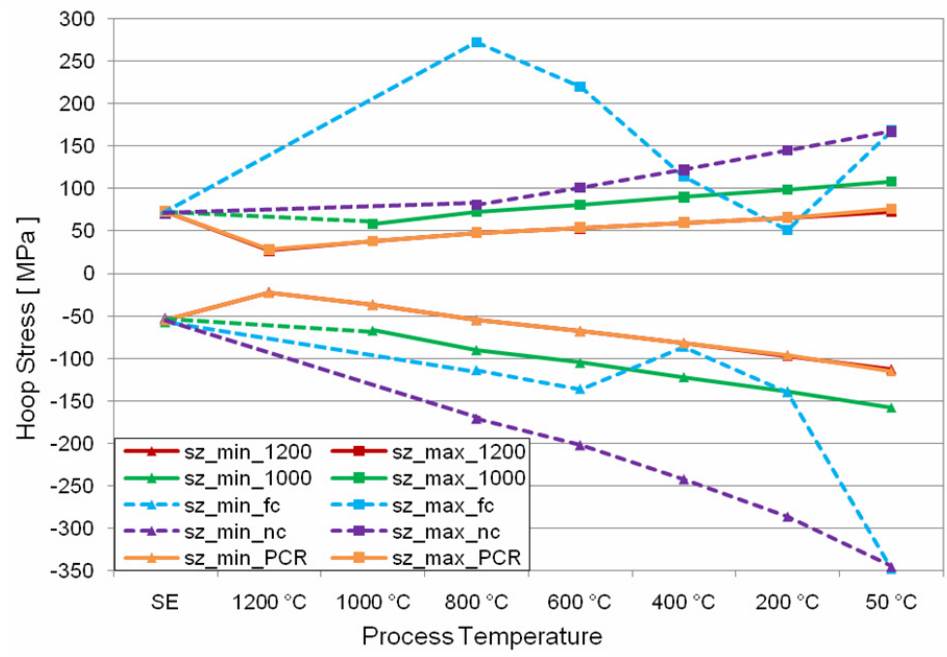

Figure 11. Hoop stress development for different heat treatment and cooling conditions, initial substrate temperature $=1100^{\circ} \mathrm{C}$.

\section{Experiments}

Some spray formed tubes are shown in Figure 12. In the following, experiments \#691 and \#692 were focused on. Except the preheating temperature $\left(1200^{\circ} \mathrm{C}\right.$ for $\# 691$ and room temperature for \#692), all the parameters were identical. The experiment started at the upper end of the deposit (blue arrow). Thermocouple 1 (TE1) moved toward the position of the spray cone, then the direction was changed and a second layer was applied to the existing deposit. Yellow lines mark positions at which samples were taken for porosity measurements. Thermocouple TE2 reached 
the position of the spray cone approximately 50s after spray process started. The surface temperature in run $\# 691$ was about $600^{\circ} \mathrm{C}$, whereas the temperature in run \#692 was considerably lower. The thermocouple measurement for that case showed a continuous increase, and not the expected sharp rise, in temperature. Therefore, a temperature of $300^{\circ} \mathrm{C}$ corresponding to Figure 6 can be assumed.

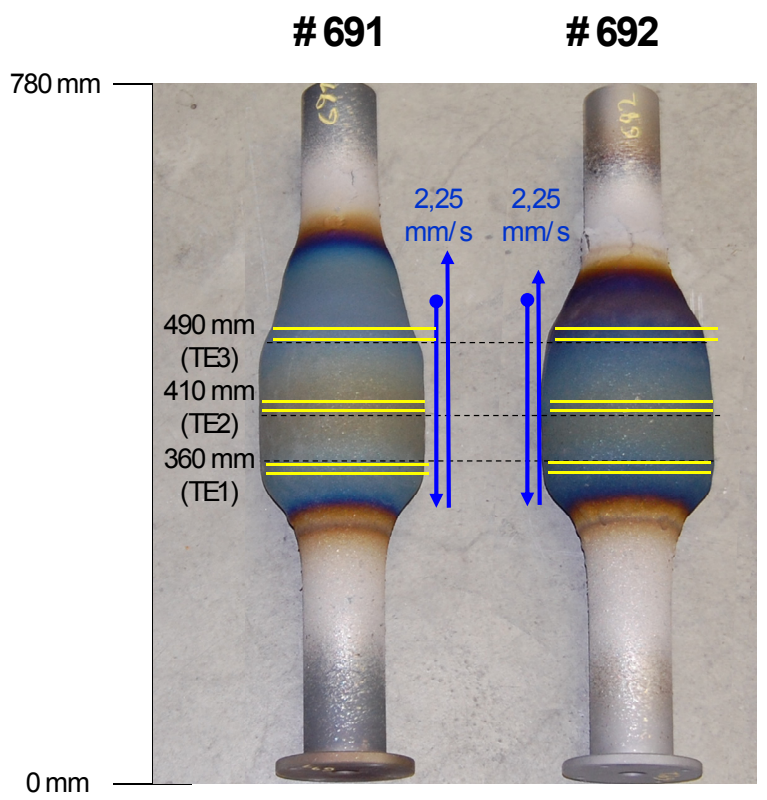

Figure 12. Experiments \#691 and \#692, yellow lines mark the sample position for porosity measurements; dashed lines are the positions for thermocouples.
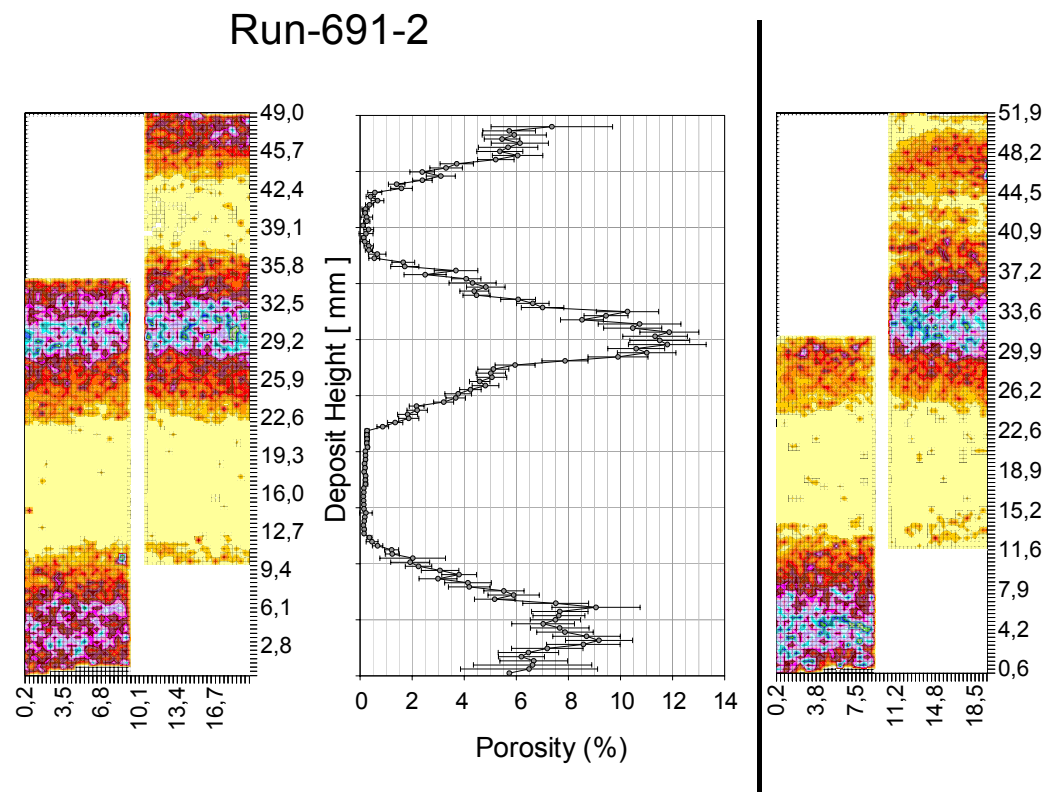

\section{Run-692-2}

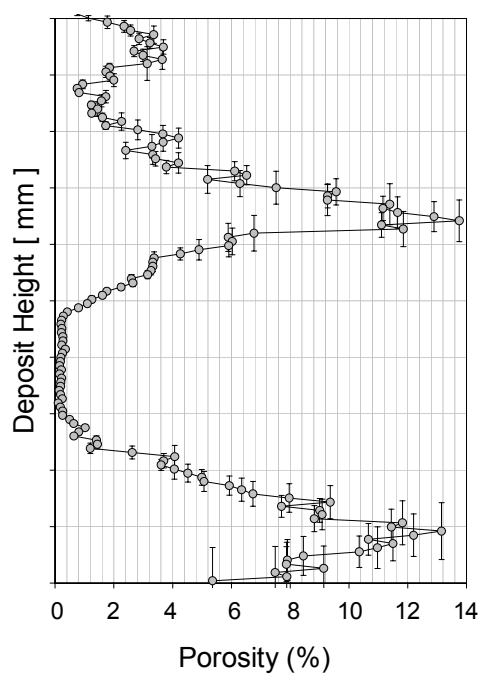

Figure 13. Distribution of porosity in two different runs at thermocouple position TE 2, run \#691 initial substrate temperature $=1200^{\circ} \mathrm{C}$, run $\# 692$, initial substrate temperature $=$ room temperature. 
The results of the porosity measurements are shown in Figure 13. The total deposit height was about 50mm (49mm in run $\# 691,51.9 \mathrm{~mm}$ in run \#692). On the left side, the probe processed in the image analysis is shown. On the right side, the porosity is plotted as function of the deposit height. The curve represents the average at the corresponding height, and the error bars show the variation. The porosity is about 6 to $8 \%$ for higher surface temperatures, whereas the porosity reaches a value of $13 \%$ for the lower surface temperatures. The decay is slightly faster for the hotter substrate. Also, the region with nearly zero porosity is extended. At the end of layer 1 , the porosity increases to values of about 4 to $6 \%$ in both cases. When the second layer was added, the porosity rises sharply to values of about 12 to $14 \%$ with slightly lower values for the initially preheated substrate. As shown in Figure 13, the surface temperature at the end of the spray process was higher than in the cold case. The porosity of the second layer for run \#691 shows the expected behavior, a decrease to nearly zero and an increase at the end of the spray process. Run \#692 shows a different result. After the decay in porosity, the value doesn't go to zero and there is no increase in porosity observed towards the end of the spray process.

\section{Summary}

This paper presents the thermal and mechanical behavior of spray formed super alloy tubes. It has been shown that the heat treatment is the key parameter in the avoidance of residual stresses. The resulting residual stresses at room temperature are not affected by the cooling conditions for the no heat treatment case. In contrast the intermediate stresses can reach significantly high values. This might be important for brittle materials which may crack. In the case of heat treatment, the key parameter is the absolute annealing temperature. Lower the annealing temperatures result in higher residual stresses. The comparison between step temperature and a defined low rate cooling shows no difference in the final residual stresses at room temperature or stresses at intermediate temperatures. At the moment of deposition, the porosity shows smaller values for higher substrate temperatures. Also, the porosity decreases more rapidly with respect to the deposit height.

\section{$\underline{\text { Acknowledgements }}$}

The authors gratefully acknowledge the German Research Foundation (DFG) for their financial support of this project under the reference number KI 284/17-1.

\section{References}

1. M. Walter, et al., "Spray Forming and Post Processing of Superalloy Rings," Proceedings of the Sixth International Symposium on Superalloys 718, 625, 706 and Derivatives, E. A. Loria, ed., (2005), 429-441.

2. R. Ristau and R. Kienzler, "Influence of Different Enthalpy Distribution on the Temperature Field of a Growing Billet," Proc. Spray Deposition and Melt Atomization SDMA, K. Bauckhage et al, eds., Bremen, (2003), 8:43-52, ISBN 3-8330-0571-8

3. R. Ristau and R. Kienzler, "Simulation of Temperature-Distributions in Spray Formed NickelBased Alloy Tubes," Proc. SDMA 2009, Spray Deposition and Melt Atomization ICSF VII, the 
7th International Conference on Spray Forming, U. Fritsching et al, eds., Bremen, (2009), ISBN 978-3-88722-710-4.

4. C. Cui, et al., "Control of Cooling During Spray Forming of Bearing Steel Billets," Materials Science and Engineering A, 383 (2004), 158-165.

5. O. Meyer, U. Fritsching and K. Bauckhage, "Numerical Investigation of Alternative Process Conditions for Influencing the Thermal History of Spray Formed Billets," Int. J. Thermal Sci., 43 (2003), 153-168.

6. C. Meyer, et al., "Thermal Simulation of Multilayer Materials Generated by Spray Forming," SDMA 2009, The 4th International Conference on Spray Deposition and Melt Atomization ICSF VII, the 7th International Conference on Spray Forming, U. Fritsching et al, eds., Bremen, (2009), ISBN 978-3-88722-710-4.

7. R. Schröder and R. Kienzler, "Numerical Simulations of Residual Stress Induced Damages of Spray Formed Components," Tagungsband der 30. Sitzung des Arbeitskreises Bruchvorgänge, DVM, Dresden (1998), 73-82.

8. N. Jordan, et al., "Influences of the Spray Deposition Process on the Properties of Copper and Copper Alloys," Materials Sciences and Engineering, A 326 (2002), 51-62.

9. K. Tustev, et al., "Behaviour of Aluminum Al 2014 at high Temperature - Experimental and Numerical Results," Proc. Spray Deposition and Melt Atomization SDMA, K. Bauckhage et al, eds., Bremen, (2003), 8:129 -136, ISBN 3-8330-0571-8.

10. www.Specialmetals (2007). "INCONEL Alloy 718." from www.specialmetals.com.

11. V. Uhlenwinkel and K. Bauckhage, "Mass Flux Profile and Local Particle Size in the Spray Cone During Spray Forming of Steel, Copper and Tin," Proc. 2nd International Conference on Spray Forming, Swansea, UK, (1993), 25-34.

12. H. S. Carslaw and J. C. Jaeger, Conduction of Heat in Solids (Oxford University Press, 1993), 17.

13. G. Pottlacher, et al., "Thermopysical Properties of Liquid and Solid Inconel 718," Thermocimica Acta, (2002), 255-267.

14. VDI-Heat-Atlas, VDI - Heat Atlas (Springer-Verlag Berlin Heidelberg, 2006) Ka1-Ka6 